\title{
Measurement and Interpretation of Connectivity of Chinese Cities in World City Network, 2010
}

Ben Derudder, Department of Geography, Ghent University, Krijgslaan 281/S8, B9000 Gent, Belgium. Email: ben.derudder@ugent.be

Peter J. Taylor, School of the Built and Natural Environment, Northumbria University, Ellison Place, Newcastle upon Tyne, NE1 8ST, UK. Email: crogfam@yahoo.com

Michael Hoyler, Department of Geography, Loughborough University, Leicestershire LE11 3TU, UK. Email: m.hoyler@lboro.ac.uk

Pengfei Ni, Chinese Academy of Social Sciences, 5, Jianguomennei Dajie, 100732 Beijing, China. Email:

nipf@cass.org.cn

Xingjian Liu, Department of Geography, University of Cambridge, Department of Geography

University of Cambridge, Downing Place, Cambridge, CB2 3EN, UK. Email: xl306@ cam.ac.uk

Miaoxi Zhao, South China University of Technology, Wushan Road,Tianhe District, 510641 Guangzhou, China. Email: arzhao@scut.edu.cn

Wei Shen, ESSCA School of Management, 1 Rue Joseph Lakanal, 49000 Angers, France. Email: wei.shen@essca.fr

Frank Witlox, Department of Geography, Ghent University, Krijgslaan 281/S8, B9000 Gent, Belgium. Email:

frank.witlox@ugent.be Abstract: This is an empirical paper that measures and interprets the position of Chinese cities in the world city network in 2010 .
Building on a specification of the world city network as an 'interlocking network' in which business services firms play the crucial role
in city network formation, information is gathered about the presence of global service firms in cities. This information is converted into
data to provide the 'service value' of a city for a firm's provision of corporate services in a 526 (cities) $\times 175$ (firms) matrix. These data
are then used as the input to the interlocking network model in order to measure cities' connectivity and its predominant geographical
orientation. Here we focus on the position of some key Chinese cities in this regard, and discuss and interpret results in the context of
the urban dimensions of the 'opening up' of the Chinese economy.

Keywords: world city network; advanced producer services; Shanghai; Hong Kong; Beijing

Citation: 2013. Measurement and interpretation of connectivity of Chinese cities in world city network, 2010. Chinese Geographical Science, 23(0): 000-000. doi: 10.1007/s11769-013-0000-0

\section{Introduction}

There is now a considerable literature on the role of cities as key nodes in an increasingly globalized economy. One expression of this can be found in recent large edited volumes: Scott (2001), Brenner and Keil (2006), Taylor et al. (2007; 2011; 2013a) and Derudder et al. (2012) muster over 300 papers between them but still represent only the tip of this particular iceberg. Within this literature, the research in the context of the Globalization and World Cities Research Network (GaWC) has pioneered a relational approach to understanding cities in globalization as a 'world city network' (WCN). In developing a theoretically grounded measurement of WCN formation, GaWC has drawn explicitly upon Sassen's (1991) seminal writings on the 'global city' as the prime production site and market for financial, professional and creative services for corporate business. Specifically, major firms across the world have 
become increasingly dependent on advanced producer services, such as financial services, accountancy, advertising, law, and management consultancy which offer customized knowledge, expertise and skills to their corporate clients. In this process, many of these service firms have become transnational enterprises in their own right as they have expanded into a growing global market to both service their existing customers and acquire new clients (Aharoni and Nachum, 2000; Harrington and Daniels, 2006). According to Sassen (1991), global cities have a particular component in their economic base that gives them a specific role in the current phase of the world economy: they are the business service centres that have a key enabling role in economic globalization.

While GaWC's WCN analyses are based upon Sassen's global city thesis, we depart from her approach in identifying more than just a select number of cities in the servicing of global capital. In this we follow Manuel Castells' (1996) argument for a network society that encompasses a 'global network' of cities that 'can not be reduced to a few urban cores at the top of the hierarchy'. For the purpose of the large-scale empirical analyses reported in this paper, the key point is that service firms have benefited immensely from the technological advances in telecommunications, allowing them to extend the geographical reach of their service provision. Thus while advanced producer service firms have always clustered in cities, in contemporary globalization they have been able to do their work through multiple offices in large numbers of cities around the world. This enables them to protect their brand integrity and offer a seamless service to their corporate clients operating in international markets (i.e. as opposed to previous instruments such as using 'correspondence banks' for clients' financial transactions). Each firm has its own strategy in terms of the location and number of cities in its office network, as well as the size and functions of individual offices. To gauge the network formation in the office networks of services firms, we employ a model that treats the work done in these offices on projects that require multiple office inputs as 'interlocking' the cities in which they are housed. Thus these intercity relations through servicing practices consist of both electronic and embodied flows (for example, online exchange of information and sharing of knowledge, as well as face-to-face meetings involving business travel). It is these 'working flows', combined across numerous projects in many firms, which constitute the WCN as specified in the GaWC model (Taylor, 2001; 2004).

A first major application of the GaWC model was the measurement (Taylor et al., 2002a) and subsequent empirical analysis (Taylor et al., 2002b; 2002c; Derudder et al., 2003; Taylor and Derudder, 2004) of the WCN in the year 2000. In practice, the analyses were based on information on the locational strategies of 100 leading business service firms in 315 cities worldwide (Taylor, 2004). Continuing GaWC's decade-long concern for mapping the WCN through the networking practices of major advances producer service (APS) firms in cities, in 2007 we joined forces with the Global Urban Competitiveness Project (GUCP) at the Chinese Academy of Social Sciences (CASS) to carry out a number of new, large-scale data collection exercises, initially for the year 2008 (Taylor et al., 2011) and subsequently for the year 2010 (Taylor et al., 2013b). In addition, we have garnered and analysed data on related features of cities' integration in the global economy, such as international banking activities (Derudder et al., 2011) and Islamic finance (Bassens et al., 2010).

Against this backdrop, the purpose of this paper is to provide, based on GaWC's most recent APS dataset (covering information on 175 office networks of firms across 526 cities), an overview of the position of Chinese cities in the WCN in 2010. Based on these results, we discuss the significance of the uneven integration of Chinese cities in the WCN in the context of the urban dimensions of China's 'opening up' to the global economy.

\section{Data and Methodology}

\subsection{Data collection}

As outlined in the introduction, our approach for measuring WCN formation is based on a measurement of the presence of major APS firms in major cities. However, without recourse to reliance on public data, the collection of a large quantity of information on private corporations is fraught with difficulty. The most obvious problem is confidentiality since, as a general rule, no corporation wants to reveal its strategies, including location decisions, to its competitors. However, APS firms are the focus of the information gathering here and they depart from this rule in one crucial respect. These firms provide knowledge-based (expert/profession/creative) services to other corporations to facilitate their business activities. Such corporate service firms have benefited immensely from the technological advances in computing and communications that have allowed them to broaden the geographical distribution of their service provision. In this situation, locational strategy is an integral part of the firm's public marketing and recruitment policies. For instance, new potential clients from around the world will want to know the geographical range of the services on offer. Also, since these are knowledge-based firms, a global scope is very obviously an important advantage in signing up the best of the next generation of key workers. Hence among APS firms, locational strategy is perforce quite transparent. Typically the websites of such firms provide an option to select 'location' giving addresses of offices, often with a world map of their distribution to emphasis their global presence (http://www.deloitte.com/view/en_GX/global/locations/index.htm). Advantage is taken of this transparency for information gathering. Our data collection strategy, therefore, is to find basic information on corporate websites on where major service firms are located.

(1) Firms 
In our research, firms were chosen by their ranking in lists of the largest firms in each sector. For financial services, the top 75 banking, insurance and diversified finance firms were identified as ranked in the Forbes composite index (http://www.forbes.com), which combines rankings for sales, profits, assets and market value. For the four other APS sectors we included the top 25 firms as follows: for accountancy the ranking by revenues (http: //www.worldaccountingintelligence.com); for advertising agencies the revenue ranking of 'marketing organizations' by Advertising Age (http://www.adage.com/); for law the Chambers Global list of corporate law firms (http://www.chambersandpartners.com/global); and for management consultancy firms the Vault Management \& Strategy Consulting Survey, which ranks firms in terms of their 'prestige' (http://www.vault.com). These lists were the latest rankings available at the planning of the research in 2009 and tended to be based on 2008 data due to the usual time-lag in reporting such data. Substitute firms were identified for each sector (ranking just below the top 75 and 25) to cover for situations where a firm had disappeared (e.g. been taken over) in the two years before the actual data collection. There is, of course, no 'objective' way to choose the exact number of firms to be included per sector; our choice to include more financial services firms is based on recent trends towards financialization in the global economy and the crucial role this entails for such firms (Pike and Pollard, 2010).

Although the starting point is firms, the information collected defines networks. Many global service firms exist as 'groups'. For instance, in accountancy there are alliances of medium-sized firms constituted as networks in order to compete globally with the very large firms that lead this sector. In other sectors, takeover activity has led to a corporate structure of core firm plus subsidiaries with the latter providing distinctive services as an additional dimension to the main service provision, for instance, as the investment arm of a mainstream bank. Sometimes the latter structure straddles the sector boundary such as banks owning insurance companies. Such firms are treated as a single network in our research and allocated to the core company's sector. Thus the GaWC selection of APS firms constitutes a large sample of 175 global service networks.

(2) Cities

A few of the larger firms have branches in many hundreds, even thousands, of cities and towns. The data collection has been restricted to the more important cities for two reasons. The first is analytical: the more cities are being included, the sparser the final matrix will become with almost no networks present in the smaller cities and towns. The second is theoretical: the interest is in the more important inter-city relations, ultimately the world city network. Nevertheless, it is also important not to omit any possible significant node in the world city network so that a relatively large number of cities need to be selected. Additionally, it is necessary to ensure that all continents are reasonably represented. The selection of cities is thus based of a number of overlapping criteria, and includes the capital cities of all but the smallest states and all cities with more than $1.5 \times 10^{6}$ inhabitants. It is these 526 cities that are used in recording information on the 175 global service networks of firms.

\subsection{Data production}

Selecting firms and cities is relatively straightforward, but attempts to measure the importance of a given city to a given firm's global service provision is more complicated: there is no simple, consistent set of information available across firms. The prime sources of information are websites and each of these is different among the 175 firms. It is therefore necessary to 'scavenge' all possible relevant available information, firm by firm, from these websites. For each firm, two types of information have been gathered. First, information about the size of a firm's presence in a city is obtained. Ideally, information on the number of professional practitioners listed as working in the firm's office in a given city is needed. Such information is widely available for law firms but is relatively uncommon in other sectors. Here other information has to be used such as the number of offices the firm has in a city. Second, the extralocational functions of a firm's office in a city are recorded. Headquarter functions are the obvious example but other features like subsidiary headquarters and regional offices are recorded. Any information that informs these two features of a firm's presence in a city is collected in this scavenger method of information gathering.

The actual problem with the scavenger method is that the type and amount of information varies immensely across the firms. For instance, some firms have geographical jurisdictions of offices that are 'regional' (transnational) in scope, others have 'national offices', or there may be 'area offices' or 'division offices' with wide variation in the geographical meaning of each category. In addition, many firms will have no specified geographical jurisdictions for any of their offices. Some information is quite straightforward as when a hierarchical arrangement is shown through contact with an office being routed through an office in another city. But it is more common to find a confusing range of information indicating the special importance of an office. In other words: APS firms' websites are a rich vein of information but much work is required to convert it into usable data to compare firms across cities.

In conversion from information to data there is always a tension between keeping as much of the original material as possible and creating a credible ordering that accommodates all degrees of information across cases. In this exercise, there is very detailed information for some firms and much less for others. This tension is resolved here by devising a relatively simple scoring system to accommodate the multifarious information gathered. A six-point scale is used where two levels are automatically given: obviously zero is scored where there is no presence of a firm in a city, and 5 is scored for the city that houses a firm's headquarters. Hence decision making on scoring focuses upon 
allocating the middle four scores $(1,2,3$, and 4$)$ to describe the service value of a firm in a city. This means that for each firm three boundary lines have to be specified: between 1 and 2, 2 and 3, and 3 and 4 .

The basic strategy of allocation is to begin with the assumption that all cities with a non-HQ presence of a firm score 2. This score represents the 'normal' or 'typical' service level of the given firm in a city. To determine such normality requires inspection of the distribution of information across all cities for that firm. To alter this score there has to be a specific reason. For instance, a city where contact with its office is referred elsewhere will be scored 1 for that firm. In other firms where there is full information on numbers of practitioners, a city with an office showing very few (perhaps none) professional practitioners would also score 1 . The point is that the boundary between 1 and 2 will differ across firms depending on information available. The same is true of the other boundaries. Generally, the boundary between 2 and 3 has been based upon size factors and that between 3 and 4 on extra-territorial factors. For instance, exceptionally large offices with many practitioners will lead to a city scoring 3 while location of regional headquarters will lead to a city scoring 4 . In practice, size and extra-territorial information have been mixed where possible in deciding on the boundaries for each firm. The end result is a service value matrix $\mathrm{V}$, a $526 \times 175$ data array of 92050 service values $v_{i, j}$ measuring the importance of city $i$ to firm network $j$, and ranging from 0 to 5 . It is these measures that will be used as the input to the network model described in the next section.

\subsection{WCN model specification}

World city network analysis implies moving beyond a mere assessment of the presence of firms in cities (i.e. a twomode network)(Liu and Derudder, 2012): the idea is that the data are used in a way that allows measuring the intercity relations created by APS firms (i.e. a one-mode network). Drawing on social network analysis research, in our research the one-mode WCN created by APS firms is best represented as an 'interlocking network' whereby the nodes (cities) are connected through constituent subcomponents (APS firms) (Taylor, 2001).

Specifying the WCN as an interlocking network, the inter-city connectivity $r_{a-i}$ between two cities $a$ and $i$ in the office networks of all firms is defined as follows:

$$
r_{a-i=100 \times j} \sum_{r_{\text {max }}} r_{a-i, j}=100 \times \frac{\left(\sum_{j} v_{a, j} \times v_{i, j}\right)}{r_{\text {max }}} \quad(a \neq i)
$$

The global network connectivity $\mathrm{GNC}_{a}$ of a city $a$ in this interlocking network is then computed by aggregating all inter-city connectivities across the network:

$$
G N C_{a}=100 \times \frac{\sum_{i} r_{a-i}}{G N C_{\text {max }}}=100 \times \frac{\left(\sum_{i, j} v_{a, j} \times v_{i, j}\right)}{G N C_{\text {max }}} \quad(a \neq i)
$$

The assumption behind this specification of the WCN as an interlocking network is that the more important an office of firm $j$ (as expressed by the service value $v_{i, j}$ ), the more links there will be with other offices in firm $j^{\prime}$ s network (i.e. a simple interaction model). The limiting case is a city that shares no firms with any other city so that all of its service value products in equations (1) and (2) are 0 and it has no connectivity. To make $r$ and GNC measures independent from the number of firms and/or cities, connectivities are usually expressed as percentages of the largest computed connectivity $r_{\max }$ and $G N C_{\max }$ in the data. Thus in our analysis below, urban connectivity $G N C_{a}$ range from $0 \%$ (no connectivity) to $100 \%$ for London (the most connected city), while inter-urban connectivities $r_{a-i}$ range from $0 \%$ (no connectivity) to $100 \%$ for London-New York (the largest inter-city connection).

Interestingly, this specification also allows the revealing of various geographical and functional patterns within overall connectivity: two cities with a similar $G N C_{a}$ may in fact be connected to very different sets of cities $r_{a-i}$. Here we will focus on two particular components of Chinese cities' connections, i.e. 1) the relative importance of Chinese cities' connections with major cities across the globe (i.e. their 'Globalism'), and 2) the relative importance of Chinese cities' connections with other major Chinese cities (i.e. their 'Localism'). Taking Shanghai as an example, for the Globalism measure, we focus on Shanghai's connections with the ten most connected non-Chinese cities in the global economy (London, New York, Paris, Singapore, Tokyo, Chicago, Dubai, Sydney, Milan, and Toronto). For the localism measure, we focus on Shanghai's connections with the 24 other major Chinese cities as emerging from our analysis (Beijing, Chengdu, Chongqing, Dalian, Fuzhou, Guangzhou, Hong Kong, Hsinchu, Kunming, Kaohsiung, Macau, Ningbo, Nanjing, Hangzhou, Qingdao, Shanghai, Suzhou, Shenyang, Shenzhen, Tianjin, Taipei, Taiyuan, Wuhan, Xi'an, and Xiamen). 
By way of example, the measures for Shanghai are computed as follows:

$$
\begin{aligned}
& \text { Globalism Shanghai }=r_{\text {Shanghai }-T O P 10}=100 \times\left(\frac{\sum_{i=1}^{T O P 10} r_{\text {Shanghai }-i}}{\sum_{i=1}^{525} r_{\text {Shanghai }-i}}-\frac{\sum_{i=1}^{T O P 10} G N C_{i}}{\sum_{i=1}^{525} G N C_{i}}\right) \\
& \text { Localism Shanghai }_{=} r_{\text {Shanghai }- \text { China } 24}=100 \times\left(\frac{\sum_{i=1}^{\text {China } 24} r_{\text {Shanghai-i }}}{\sum_{i=1}^{525} r_{\text {Shanghai }-i}}-\frac{\sum_{i=1}^{\text {China } 24} G N C_{i}}{\sum_{i=1}^{525} G N C_{i}}\right)
\end{aligned}
$$

Using Shanghai's Globalism as an example, it can be seen that the results of this measure are to be interpreted as follows: a positive value would imply that Shanghai has stronger connections with the top 10 cities than expected; a negative value would imply that Shanghai has weaker connections with the top 10 cities than expected; and the larger the value, the stronger this overall tendency. As a consequence, a value 'close' to zero would imply that Shanghai has connections with the top 10 cities that are neither particularly strong nor weak based on what can be expected from the involved cities' overall connectivities. Note that this is a relative measure that is therefore in principle independent from a city's overall connectivity. Localism scores can be interpreted along similar lines.

And finally, to gauge the dominant orientation of a city's connection, we simply compare the strength of both measures as follows:

Dominant $_{\text {Orientation }}$ Shanghai $=$ Globalism $_{\text {Shanghai }}-$ Localism $_{\text {Shanghai }}$

Positive values point to cities that are more oriented towards key cities in the global economy, negative values to cities that are more oriented towards cities in the own country. Again, the larger the value is, the stronger the tendency is. Given strong regional tendencies in the WCN (Taylor et al., 2011; 2013b), most cities have an inward orientation (and therefore negative values). In the next section, we use these data/measures to present an empirical description of the position of Chinese cities in the WCN anno 2010.

\section{Results}

\subsection{Network connectivity}

Table 1 presents an overview of the 20 cities with the largest global network connectivity $r_{a-i}$ and $G N C_{a}$ in 2010 . Our analysis shows that London, New York, and Hong Kong are by far the most connected cities in the WCN created by globalized APS firms, with NY-LON as the undisputed dominant dyad (a longstanding pattern in this kind of analysis, see Derudder et al., 2003). Beyond this clear-cut top three, there are a number of cities with comparable connectivity, whereby perhaps the most remarkable geographical feature is that cities from very different parts of the world boast major connectivity. As suggested by Sassen (1994), the WCN seems to cut across erstwhile North/South and East/West divides, with major connectivity for cities as diverse as Shanghai, Sao Paulo, Sydney, Toronto, Mumbai and Milan.

Table 1 Largest values for $\mathrm{r}_{\mathrm{a}-\mathrm{i}}$ and $\mathrm{GNC}_{a}$ of 20 most connected cities in WCN in 2010.

\begin{tabular}{|c|c|c|c|c|c|}
\hline Global ranking & \multicolumn{2}{|c|}{ City-pair } & $\mathrm{r}_{\mathrm{a}-\mathrm{i}}$ ir & City & GNCa in $\%$ \\
\hline 1 & New York & London & 100 & London & 100 \\
\hline 2 & London & Hongkong & 75.0 & New York & 94.4 \\
\hline 3 & New York & Hongkong & 69.0 & Hong Kong & 73.0 \\
\hline 4 & Singapore & London & 66.5 & Paris & 68.3 \\
\hline 5 & Paris & London & 66.2 & Singapore & 67.5 \\
\hline 6 & Singapore & New York & 62.1 & Tokyo & 63.8 \\
\hline
\end{tabular}




\begin{tabular}{|c|c|c|c|c|c|}
\hline 7 & Shanghai & London & 62.1 & Shanghai & 62.7 \\
\hline 8 & Paris & New York & 61.3 & Chicago & 61.6 \\
\hline 9 & London & Chicago & 59.2 & Dubai & 61.4 \\
\hline 10 & Shanghai & New York & 58.7 & Sydney & 61.1 \\
\hline 11 & Tokyo & London & 58.5 & Milan & 58.9 \\
\hline 12 & New York & Chicago & 57.6 & Beijing & 58.4 \\
\hline 13 & Tokyo & New York & 55.7 & Toronto & 58.3 \\
\hline 14 & London & Beijing & 55.6 & Sao Paulo & 55.7 \\
\hline 15 & London & Dubai & 53.5 & Madrid & 55.2 \\
\hline 16 & New York & Los Angeles & 53.1 & Mumbai & 55.2 \\
\hline 17 & Los Angeles & London & 53.0 & Los Angeles & 55.1 \\
\hline 18 & Sydney & London & 52.6 & Moscow & 54.3 \\
\hline 19 & New York & Beijing & 52.3 & Frankfurt & 52.6 \\
\hline 20 & Singapore & Hongkong & 51.6 & Mexico & 52.5 \\
\hline
\end{tabular}

Table 2 and Fig. 1 provide an overview of the 25 Chinese cities with a $\mathrm{GNC}_{a}$ larger than $5 \%$ in 2010. Table 2 shows that Hong Kong, Shanghai and Beijing are playing in their own league as these cities have far bigger connectivity than the other Chinese cities. Beyond this clear-cut top three, only Taipei as a special case and Guangzhou/Shenzhen are reasonably well connected in the office networks of global APS firms. Other major cities such as Nanjing and Chengdu, but perhaps especially Chongqing and Wuhan are far less connected in the WCN in spite of their size and unmistakeable economic importance within the Chinese space-economy (Ni, 2012).

Table $2 \mathrm{GNC}_{a}$ of the 25 most connected Chinese cities in WCN in 2010.

\begin{tabular}{|c|c|c|c|}
\hline Chinese ranking & Global ranking & City & $\mathrm{GNC}_{a}(\%)$ \\
\hline 1 & 3 & Hong Kong & 73.0 \\
\hline 2 & 7 & Shanghai & 62.7 \\
\hline 3 & 12 & Beijing & 58.4 \\
\hline 4 & 43 & Taibei & 41.7 \\
\hline 5 & 67 & Guangzhou & 34.1 \\
\hline 6 & 106 & Shenzhen & 25.8 \\
\hline 7 & 188 & Tianjin & 16.8 \\
\hline 8 & 223 & Kaohsiung & 14.3 \\
\hline 9 & 245 & Nanjing & 13.5 \\
\hline 10 & 252 & Chengdu & 13.1 \\
\hline 11 & 262 & Hangzhou & 12.5 \\
\hline 12 & 267 & Qingdao & 12.3 \\
\hline 13 & 275 & Dalian & 12.0 \\
\hline 14 & 291 & Macao & 10.9 \\
\hline 15 & 319 & Chongqing & 8.9 \\
\hline 16 & 323 & Xi'an & 8.7 \\
\hline 17 & 325 & Suzhou & 8.6 \\
\hline 18 & 337 & Wuhan & 8.0 \\
\hline 19 & 346 & Xiamen & 7.5 \\
\hline 20 & 348 & Ningbo & 7.5 \\
\hline 21 & 356 & Shenyang & 7.2 \\
\hline 22 & 359 & Fuzhou & 7.1 \\
\hline 23 & 361 & Hsinchu & 7.1 \\
\hline
\end{tabular}




\begin{tabular}{|l|l|c|c|}
\hline 24 & 367 & Taiyuan & 6.7 \\
\hline 25 & 401 & Kunming & 5.1 \\
\hline
\end{tabular}

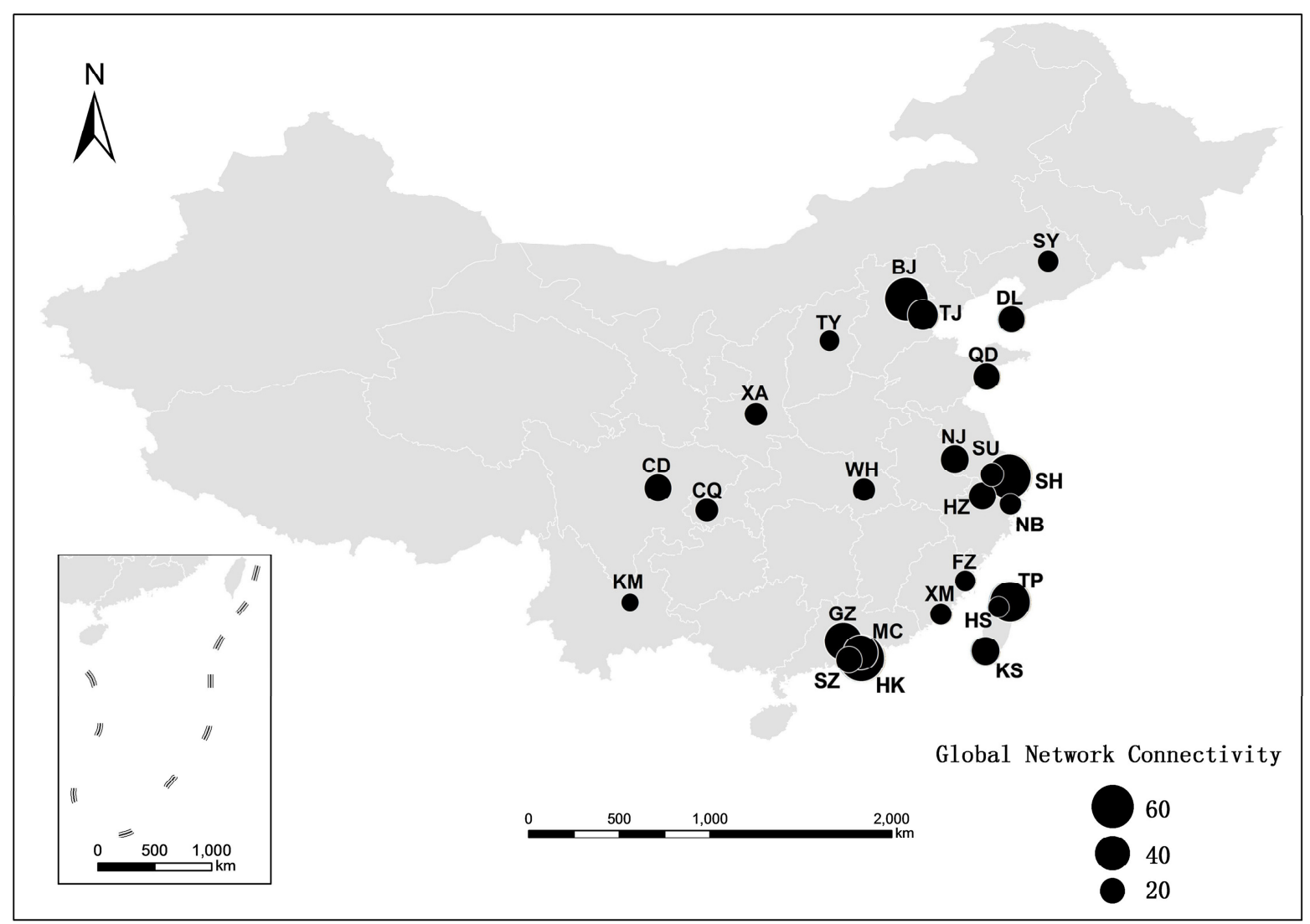

Fig. $1 \mathrm{GNC}_{a}$ of the 25 most connected Chinese cities in WCN in 2010. Codes for cities are as follows: BJ: Beijing; CD: Chengdu; CQ: Chongqing; DL: Dalian; FZ: Fuzhou; GZ: Guangzhou; HK: Hong Kong; HS: Hsinchu; KM: Kunming; KS: Kaohsiung; MC: Macau; NB: Ningbo; NJ: Nanjing; HZ: Hangzhou; QD: Qingdao; SH: Shanghai; SU: Suzhou; SY: Shenyang; SZ: Shenzhen; TJ: Tianjin; TP: Taipei; TY: Taiyuan; WH: Wuhan; XA: Xi'an; XM: Xiamen.

The particular roles of Hong Kong, Shanghai and Beijing are confirmed in Table 3 and Fig. 2, which bring together the Globalism scores for Chinese cities. Remarkably, although Globalism scores are relative scores that have no direct relation with overall connectivities, these rankings are nonetheless clearly interrelated: Hong Kong, Shanghai and Beijing do not only stand out because of their sheer overall connectivity in comparison to other Chinese cities scores, but also because of the strength of their connections with the world's leading cities. Beyond this top three and Taipei, the relation is slightly less clear-cut, although it is notable that overall only seven cities feature above-average connections with the world's 10 most connected non-Chinese cities. In the case of the Guangzhou/Shenzhen pair, Guangzhou seems much stronger connected to key cities in the global economy than Shenzhen in terms of its business service connections. Meanwhile, Wuhan features relatively strong connections with the world's major cities in spite of a having a rather average $\mathrm{GNC}_{a}$ overall.

Table 3 Globalism of the 25 most connected Chinese cities in WCN in 2010.

\begin{tabular}{|c|c|c|}
\hline Rank & City & Globalism \\
\hline 1 & Hongkong & 3.11 \\
\hline 2 & Shanghai & 2.87 \\
\hline 3 & Beijing & 2.68 \\
\hline 4 & Taibei & 1.72 \\
\hline 5 & Guangzhou & 1.05 \\
\hline 6 & Wuhan & 1.04 \\
\hline
\end{tabular}




\begin{tabular}{|c|c|c|}
\hline 7 & Tianjin & 0.28 \\
\hline 8 & Dalian & -0.30 \\
\hline 9 & Chengdu & -0.60 \\
\hline 10 & Xiamen & -0.65 \\
\hline 11 & Suzhou & -0.68 \\
\hline 12 & Shenzhen & -0.69 \\
\hline 13 & Shenyang & -0.69 \\
\hline 14 & Taiyuan & -0.72 \\
\hline 15 & Qingdao & -0.76 \\
\hline 16 & Nanjing & -0.79 \\
\hline 17 & Kunming & -0.86 \\
\hline 18 & Chongqing & -0.98 \\
\hline 19 & Macao & -1.05 \\
\hline 20 & Hangzhou & -1.11 \\
\hline 21 & Fuzhou & -1.12 \\
\hline 22 & Xi'an & -1.44 \\
\hline 23 & Kaohsiung & -1.73 \\
\hline 24 & Ningbo & -2.24 \\
\hline 25 & Hsinchu & -2.49 \\
\hline
\end{tabular}

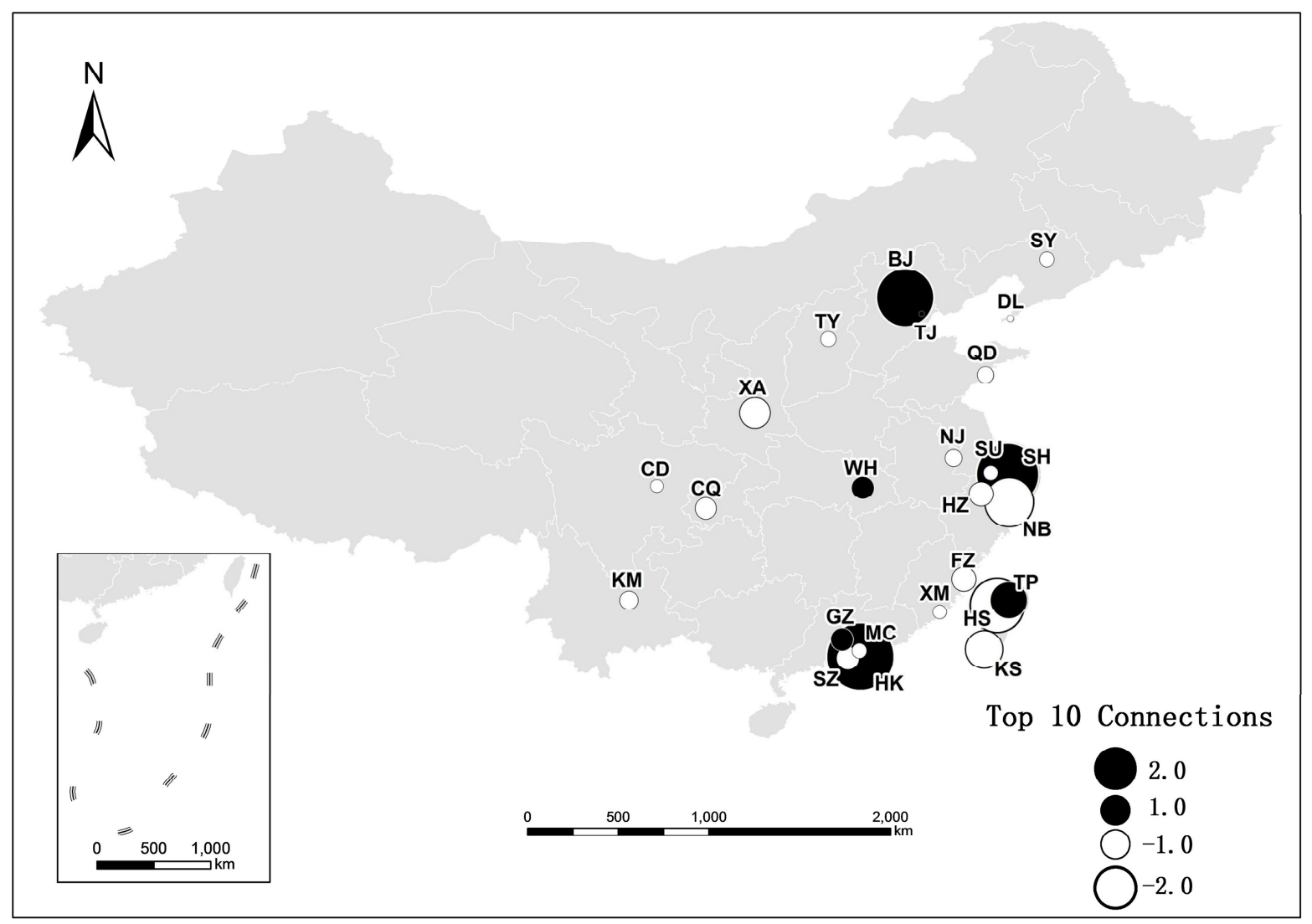

Fig. 3 Globalism of the 25 most connected Chinese cities in WCN in 2010.

Table 4 and Fig. 3 show Chinese cities according to the relative strength of their connections with other Chinese cities. Although not exactly the obverse, the ranking is related to those Table 3 in that cities with major global orientations are also the least local. This reading is complicated by the fact that cities of Taivan Province (Taibei, 
Kaohsiung, Hsinchu City) are much less connected to the remainder of China's cities because of obvious (geo) political reasons, while Wuhan complements its sizable connections with major global cities with a very strong position in the Chinese urban network. In addition, all cities record positive values, showing that within China's main cities myriad (emerging) global connections, there continues to be a distinctively Chinese layer of inter-city networking (Ni, 2012).

Table 4 Localism of the 25 most connected Chinese cities in WCN in 2010.

\begin{tabular}{|c|c|c|}
\hline Rank & City & Localism \\
\hline 1 & Kunming & 11.04 \\
\hline 2 & Wuhan & 10.02 \\
\hline 3 & Shenyang & 9.42 \\
\hline 4 & Taiyuan & 9.26 \\
\hline 5 & Xiamen & 9.17 \\
\hline 6 & Chongqing & 8.92 \\
\hline 7 & Fuzhou & 8.13 \\
\hline 8 & Suzhou & 7.98 \\
\hline 9 & Xi'An & 7.25 \\
\hline 10 & Ningbo & 6.88 \\
\hline 11 & Qingdao & 6.76 \\
\hline 12 & Dalian & 6.52 \\
\hline 13 & Chengdu & 6.50 \\
\hline 14 & Tianjin & 6.19 \\
\hline 15 & Hangzhou & 6.13 \\
\hline 16 & Nanjing & 5.84 \\
\hline 17 & Shenzhen & 4.59 \\
\hline 18 & Guangzhou & 3.57 \\
\hline 19 & Beijing & 3.34 \\
\hline 20 & Macao & 3.17 \\
\hline 21 & Shanghai & 3.01 \\
\hline 22 & Hongkong & 2.48 \\
\hline 23 & Hsinchu City & 1.94 \\
\hline 24 & Kaohsiung & 1.42 \\
\hline 25 & Taipei & 1.37 \\
\hline
\end{tabular}




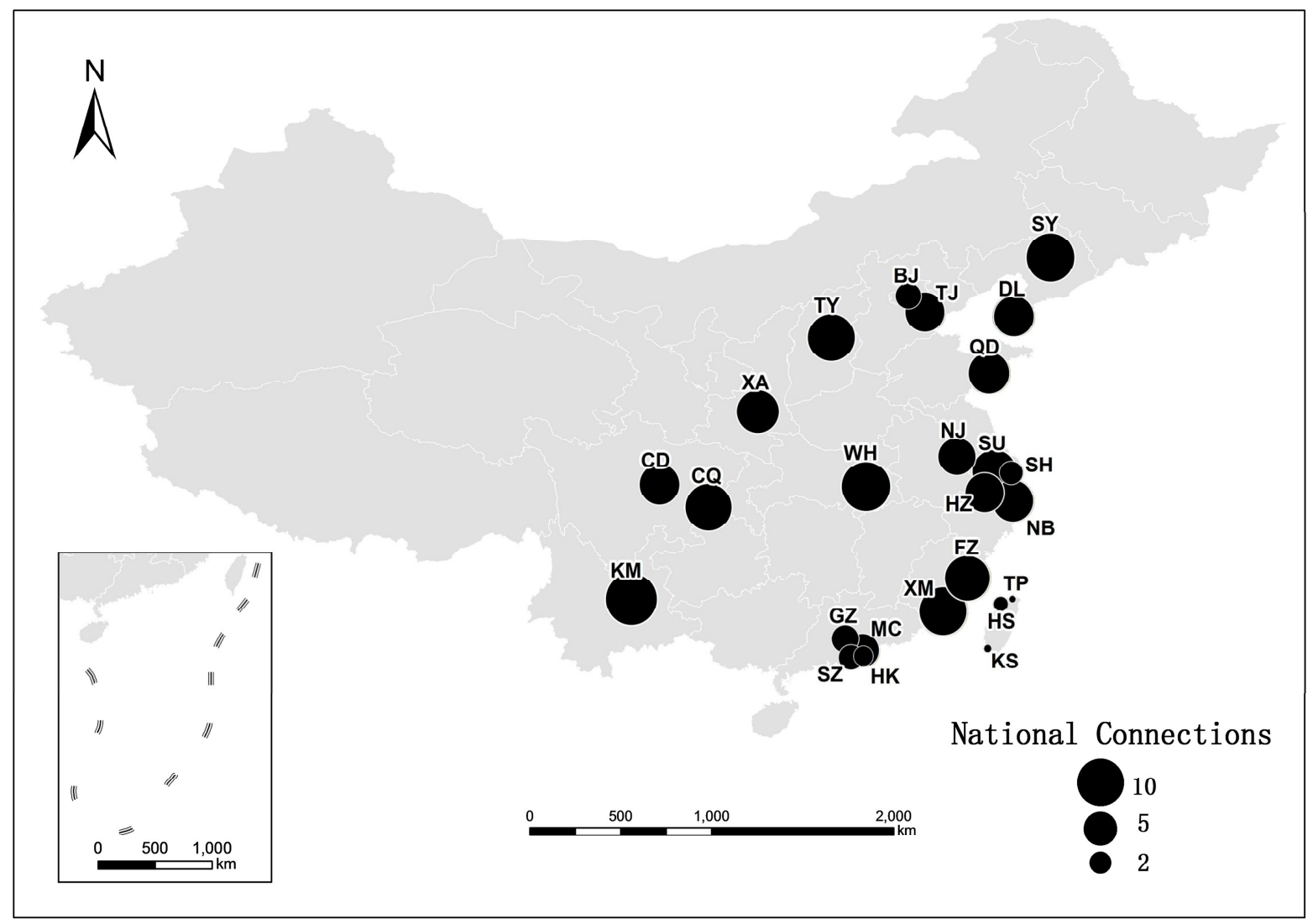

Fig. 3 Localism of the 25 most connected Chinese cities in WCN in 2010.

And finally, Table 5 and Fig. 4 combine the information in Figs. 2-3 and Tables 3-4 by revealing the dominant orientation of Chinese cities in the networks of major APS firms. In line with earlier findings for cities across very different parts of the world, almost all Chinese cities have stronger national connections than connections with the world's dominant global cities. The two exceptions are readily plausible: Hong Kong and Taibei. Beyond Hong Kong and Taipei, only Shanghai and Beijing (and to a lesser extent Guangzhou) have global connections that are not dwarfed by their national connections. Between these five cities and the rest of major cities of the mainland of China that are constantly dominated by national connections, a number of other particular cases of somewhat less 'national' cities show the credibility of our model (i.e. Hsinchu City, Kaohsiung, and Macau).

Table 5 Dominant orientation of the 25 most connected Chinese cities in WCN in 2010 (positive values point to relatively more 'global' orientations).

\begin{tabular}{|c|c|c|}
\hline Rank & City & Global orientation \\
\hline 1 & Hongkong & 0.63 \\
\hline 2 & Taibei & 0.35 \\
\hline 3 & Shanghai & -0.14 \\
\hline 4 & Beijing & -0.66 \\
\hline 5 & Guangzhou & -2.52 \\
\hline 6 & Kaohsiung & -3.15 \\
\hline 7 & Macao & -4.23 \\
\hline 8 & Hsinchu & -4.43 \\
\hline 9 & Shenzhen & -5.28 \\
\hline 10 & Tianjin & -5.91 \\
\hline 11 & Nanjing & -6.63 \\
\hline 12 & Dalian & -6.82 \\
\hline
\end{tabular}




\begin{tabular}{|c|c|c|}
\hline 13 & Chengdu & -7.10 \\
\hline 14 & Hangzhou & -7.24 \\
\hline 15 & Qingdao & -7.51 \\
\hline 16 & Suzhou & -8.69 \\
\hline 17 & Xi'An & -8.98 \\
\hline 18 & Wuhan & -9.12 \\
\hline 19 & Ningbo & -9.25 \\
\hline 20 & Fuzhou & -9.82 \\
\hline 21 & Xiamen & -9.90 \\
\hline 22 & Chongqing & -9.98 \\
\hline 23 & Taiyuan & -10.12 \\
\hline 24 & Shenyang & -11.91 \\
\hline 25 & Kunming & \\
\hline & & \\
\hline
\end{tabular}

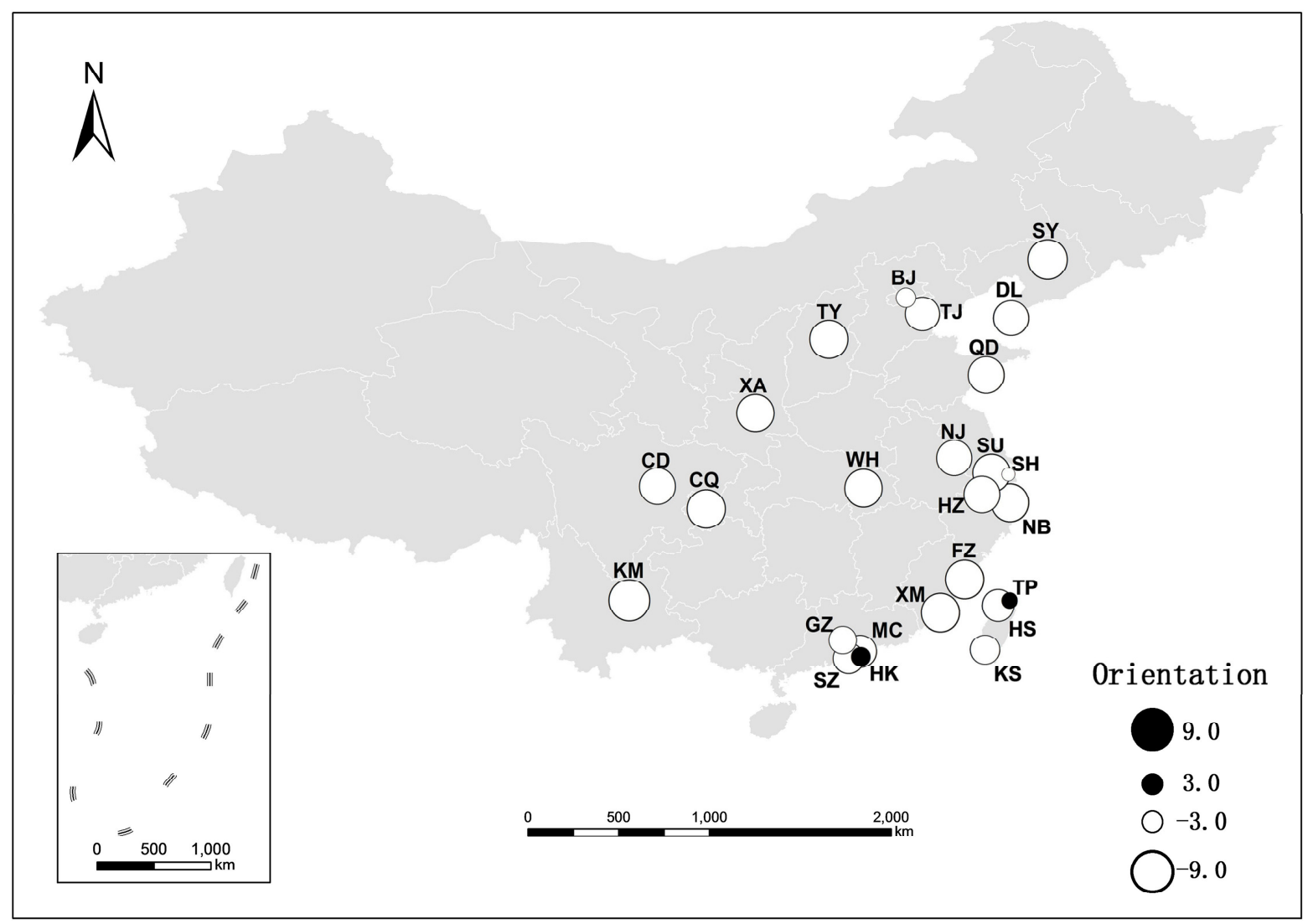

Fig. 4 Global orientation of the 25 most connected Chinese cities in WCN in 2010 (positive values point to relatively more 'global' orientations).

\subsection{Interpretation and discussion}

To show how such a large-scale quantitative approach can be used in in-depth studies of Chinese cities in globalization, we conclude this results section by briefly elaborating on some possible implications and interpretations of the empirical outcomes summarized in the previous section. Four obvious examples abound.

First, based on an evaluation of changes in the WCN in the period 2000-2008, Derudder et al. (2010) recently came to the conclusion that cities in Pacific Asia in general and China in particular have become more connected during (roughly) the past decade. However, some cities witnessed far greater leaps in connectivity than others, whereby the rise of Shanghai and Beijing alongside Hong Kong stands out. These three cities have thus become the principal gateways for the channelling of transnational flows of capital, goods, knowledge and people into China, 
and our results corroborate this reading for 2010. This does, however, not imply that Shanghai and Beijing are becoming 'little Hong Kongs', quite the contrary. Indeed, Lai (2012) has convincingly argued that these three cities play very different, complementary roles in the Chinese context. Perhaps the single most important feature of this 'context' is that China's evolution towards capitalism has been fast but in a way also gradual through the continuing imprint of the Party-state, resulting in a state-led transformation of the economy towards a unique variety of capitalism (Ma, 2002; Lin, 2011).

Most notably, in spite of China's WTO ascension in 2001, doing business continues to be tightly regulated in China. The most obvious example, of course, is that of banking in that most of China's own financial institutions continue to be state owned and governed (Chiu and Lewis, 2006). Nonetheless, one could argue that China's entry into the WTO in 2001 has created opportunities in China's major cities for foreign financial services firms as well. However, there continue to be strict rules regulating foreign financial institutions' possibilities as epitomized by the post-WTO ascension policy document 'Rules for Implementing the Regulations Governing Foreign Financial Institutions in the People's Republic of China' (Chiu and Lewis, 2006). The rules provide detailed regulations for implementing the administration of the establishment, registration, scope of business, qualification, supervision, dissolution and liquidation of foreign financial institutions. Since then, some regulatory restrictions have been lifted: foreign financial institutions were permitted to provide local currency business to all Chinese clients by the end of 2006, while five non-mainland banks were allowed to issue bank cards in China in 2007. Interestingly, however, some of the restrictions had (and continue to have) a geographical dimension. For instance, geographical restrictions on Renminbi-denominated business-the supposed golden grail for many foreign banks-have been phased out unevenly, with Shanghai amongst the first sites where this type of regulation was loosened. Unsurprisingly, therefore, the non-Chinese financial services firms in our data firms have flocked to Shanghai as this is the place where they can develop their China-centred businesses in the best circumstances in regulatory terms. Furthermore, in the face of this spatio-temporal unevenness in phasing out financial services restrictions, a city such as Shanghai has acquired a comparative advantage that is being reproduced as foreign banking involvement in China rises as the state slowly lifts some of its grip.

Second, and related to the first point, although the average connectivity and limited global orientation of a city such as Shenzhen may at first seem to be counterintuitive, this may also be in part a consequence of China's approach to 'loosening' financial restrictions. It is well known that Shenzhen boasts the only Chinese major stock exchange alongside Shanghai's, but echoing Lai's (2012) emphasis on functional specializations amongst Chinese cities, Pauly (2011) highlights that the expanding equity and banking markets in Shenzhen mainly cater to small firms focused on the domestic Chinese market, and are linked to supply chains controlled by larger state-owned enterprises. Put differently: Chinese authorities see the Shenzhen stock exchange above all as a mechanism for propelling domestic economic growth rather than making it into a 'global city' per se (in spite of some of the rhetoric). Furthermore, although the Shenzhen stock market does list shares in foreign currency for foreign investors, government planners continue to limit the liquidity of the market and to subject share prices to abrupt changes in policy. This also occurs in the face of a situation where most firms entering these markets already had complicated ownership structures, with much of their equity 'non-negotiable', i.e., primarily controlled by governmental entities (Pauly, 2011). A major consequence of all this is that, although the market capitalization of the Shenzhen equity markets has boomed, the larger financial context surrounding them remains blurred by a range of policies intended to steer capital flows within China and across its borders (as well as by regulatory opacity and inconsistency). In this context, it is no surprise that in our results Shenzhen has a different stature than, say Shanghai in terms of 'globalism' and 'orientation'.

Third, over and above this 'hard', regulatory elucidation of the uneven involvement of 'global' APS firms in Chinese cities, there may also a more subtle reason for this 'bias' towards Shanghai and Beijing alongside Hong Kong as a 'established' node in the WCN. This can be clarified by returning to the observation that regulatory restrictions and standards are less onerous in the Hong Kong market compared to Shenzhen, and certainly compared to major metropolises in China that are even less well-known outside China. The ensuing geographical unevenness regarding the inside knowledge in the functioning of the market and of associated government plans leads to a hierarchy of centres with implicit 'seals of approval' for APS firms wishing to conduct business in China's major cities. Consider, for instance, the following excerpt from a recent article on the involvement of Australian financial services firms in China in the 'Australia China Connections' business bulletin, featuring a description of National Australia Bank's (NAB) recently inaugurated Shanghai boardroom: the boardroom alone boasts one of Shanghai's most spectacular scenes with the awe-inspiring sight of the delicate tiers of Shanghai's famous Jinmao Tower and the imposing World Financial Centre beside it. From another corner, is a sweeping view of the Bund with all its colonial-era custom and banking houses and the 24-hour hustle and bustle of China's endless commerce floating up the Huangpu on the back of barges and giant container ships. If the executives at NAB needed any more reason to justify their China investment, they need only look out the window (Loras, 2011). 
There is, in other words, a sort of comfortable familiarity and reassurance associated with doing business in/from a city such as Shanghai. It 'comes close' to doing business in New York, London, or Hong Kong, and the perceived relevance and value of 'being there' is an integral part of the Shanghai experience.

And fourth and finally, geographical context equally plays an important part. We already noted that the rather limited global orientation of Shenzhen is probably related to the city's relative focus on state-owned enterprises However, Shenzhen's vicinity to Hong Kong and Guangzhou, two other premier global nodes may also play a crucial role, as major APS firms may opt to open an office in Hong Kong and/or Guangzhou to service the entire Zhujiang (Pearl) River Delta. Such a pattern, which is consistent with some of the recent research on the global connectivity of European cities in polycentric mega-city regions (Hall and Pain, 2006), would produce connectivities along the lines we are observing here, with a connectivity profile for Shenzhen that is both somewhat more restricted and less global in nature. This reading is supported by the minimal and rather local connectivities of cities such as Suzhou, Ningbo, Nanjing and Hangzhou, major cities located in the relative vicinity of Shanghai in the Changjiang (Yangtze) River Delta. Indeed, the above-mentioned example of the Australian Bank NAB and its preference for Shanghai may help explaining why, although being a major urbanized region, the Changjiang River Delta has only one major urban eyecatcher in the form of Shanghai from the perspective of globalized APS firms. And finally, this may also explain why Wuhan boasts relatively strong Chinese and global connections, as it is, in relative terms, one of the most monocentric urban regions in China.

\section{Conclusions}

The main purpose of this paper has been to provide researchers with a backcloth for reference when studying Chinese cities in globalization. We emphasize that our approach represents but one specific vantage point in the quantitative analysis of cities in globalization. Other analytical frameworks exist in the literature, and these may or may not generate different results. Nonetheless, we believe that our approach is of particularly relevant: (1) conceptually, because of our focus on key agents in the city network formation process; but also (2) methodologically, because our approach allows disentangling a city's overall 'importance' (here measured as GNC) in its constituent geographical arrangements. In this paper, we focused on two examples of such configurations (Globalism and Localism), but there are myriad other possibilities depending on the research question at hand. Future research could include more refined and diverse geographical appraisals of cites' connectivity.

In addition to parallel empirical approaches, it is clear that the various tables and maps also needs to be complemented with qualitative research, which would provide a more in-depth understanding of the stature of individual cities as well as how these patterns have come about. In the previous section, we have singled out four possible clarifications, but much more work needs to be done along these lines. However, it is clear that we will not be able to properly frame the discussion on the role of China's cities in the global economy unless we have a good understanding of their position in the WCN. We hope that the findings presented in this paper provide a good starting for such an understanding.

\section{References}

Aharoni Y, Nachum L, 2000. Globalization of Services: Some Implications for Theory and Practice. London: Routledge.

Bassens D, Derudder B, Witlox F, 2010. Searching for the Mecca of finance: Islamic financial services and the world city network. Area, 42(1): 35-46. doi: 10.1111/j.1475-4762.2009.00894.x

Brenner N, Keil R, 2006. The Global Cities Reader. London: Routledge.

Bryson J, Daniels P W, 1998. Service Industries in the Global Economy. Cheltenham: Edward Elgar.

Castells M, 1996. The Rise of The Network Society. Oxford: Blackwell.

Chiu B, Lewis M K, 2006. Reforming China's State-owned Enterprises and Banks. Cheltenham: Edward Elgar.

Derudder B, Hoyler M, Taylor P J et al., 2012. International Handbook of Globalization and World Cities. Cheltenham: Edward Elgar.

Derudder B, Taylor P J, Witlox F et al., 2003. Hierarchical tendencies and regional patterns in the world city network: A global urban analysis of 234 cities. Regional Studies, 37(9): 875-886. doi: 10.1080/0034340032000143887

Derudder B, Taylor P J, Ni P et al., 2010. Pathways of change: shifting connectivities in the world city network, 2000-2008. Urban Studies, 47(9): 1861-1877. doi: 10.1177/0042098010372682

Derudder B, Hoyler M, Taylor P J, 2011. Goodbye Reykjavik: international banking centres and the global financial crisis. Area, 43(2): 173-182. doi: 10.1111/j.1475-4762.2010.00968.x

Derudder B, Hoyler M, Taylor P J et al., 2012. International Handbook of Globalization and World Cities. Cheltenham: Edward Elgar. Hall P, Pain K, 2006. The Polycentric Metropolis: Learning from mega-city regions in Europe. London: Earthscan. Harrington J W, Daniels P W , 2006. Knowledge-based Services, Internationalization and Regional Development. Aldershot: Ashgate. 
Lai K, 2012. Differentiated Markets: Shanghai, Beijing and Hong Kong in China's Financial Centre Network. Urban Studies, 49(6): 1275-1296. doi: 10.1177/0042098011408143

Liu X, Derudder B, 2012. Two-mode networks and the interlocking world city network model: A reply to Neal. Geographical Analysis 44: 171-173.

Loras S, 2011. Financial services cover story: Australian banks in China. Australia China Connections. Available at: http://www.chinaconnections.com.au/en/magazine/back-issues/77-augsept-2011/1037-financial-services-cover-story-australianbanks-in-china

Ma L J C, 2002. Urban transformation in China, 1949-2000: A review and research agenda. Environment and Planning A, 34(9): 15451569. doi: $10.1068 / \mathrm{a} 34192$

Ni P, 2012. The Global Urban Competitiveness Report 2011. Cheltenham: Edward Elgar.

Pauly L W, 2011. Hong Kong's financial center in a regional and global context. Hong Kong Journal, 2011-7-22. Available at: http://www.hkjournal.org/archive/2011_fall/2.htm

Pike A, Pollard J, 2010. Economic Geographies of Financialization. Economic Geography, 86(1): 29-51.

Sassen S, 1991. The Global City: New York, London, Tokyo. Princeton, NJ: Princeton University Press.

Sassen S, 1994. Cities in a World Economy. Thousand Oaks, CA: Pine Forge Press.

Scott A J, 2001. Global City-Regions: trends, Theory, Policy. Oxford: Oxford University Press.

Taylor P J, 2001. Specification of the world city network. Geographical Analysis, 33(2): 181-194. doi: 10.1111/j.15384632.2001.tb00443.x

Taylor P J, 2004. World City Network: A Global Urban Analysis. London: Routledge.

Taylor P J, Catalano G, Walker D R F, 2002a. Measurement of the world city network, Urban Studies, 39(13): 2367-2376. doi: $10.1080 / 00420980220080011$

Taylor P J, Catalano G, Walker D R F, 2002b. Exploratory analysis of the world city network. Urban Studies, 39(13): 2377-2394. doi: 10.1080/0042098022000027013

Taylor P J, Walker D R F, Catalano G, Hoyler M, 2002c. Diversity and power in the world city network. Cities, 19(4): 231-241. doi: 10.1016/S0264-2751(02)00020-3

Taylor P J, Derudder, B, 2004. Porous Europe: European cities in global urban arenas. Tijdschrift voor Economische en Sociale Geografie, 95(5): 527-538. doi: 10.1111/j.0040-747X.2004.00337.x

Taylor P J, Derudder B, Saey P et al., 2007. Cities in Globalization: Practices, Policies and Theories. London: Routledge.

Taylor P J, Ni P, Derudder B et al., 2011. Global Urban Analysis: A Survey of Cities in Globalization. London: Earthscan.

Taylor P J, Hoyler M, Beaverstock J V et al., 2013a. Global Cities (4 version), London: Routledge Major Works

Taylor PJ, Derudder B, Hoyler M et al., 2013b. New Regional Geographies of the World as Practised by Leading Advanced Producer

Service Firms in 2010. Transactions, Institute of British Geographers, in press. doi:10.1111/j.1475-5661.2012.00545.x 